\title{
Synergism in anticorrosive paints
}

\author{
G BLUSTEIN ${ }^{1,2, *}$, C DEYÁ ${ }^{1,2}$ and R ROMAGNOLI ${ }^{1,2}$ \\ ${ }^{1}$ CIDEPINT (CONICET-CICPBA): Centro de Investigación y Desarrollo en Tecnología de Pinturas, \\ Calle 52e/121 y 122, (B1900AYB), La Plata 1900, Argentina \\ ${ }^{2}$ Universidad Nacional de La Plata, La Plata 1900, Argentina
}

MS received 17 June 2015; accepted 21 January 2016

\begin{abstract}
The present work depicts synergism anticorrosive behaviour between zinc hypophosphite and zinc phosphate in a commercial pigment mixture. Also, the performance of anticorrosive paints was evaluated. Synergism anticorrosive behaviour was evaluated by corrosion potential and linear polarization measurements in pigment suspensions. The protective layer obtained with this pigment mixture was investigated by scanning electron microscopy (SEM). Then, the anticorrosive properties of the pigment were assessed by incorporating it into alkyd and epoxy paints which were evaluated by salt spray test and electrochemical noise technique. The morphology and the nature of the protective layer grown under the paint film were also studied by SEM. Experimental results showed that improved anticorrosion protection is achieved in paints with reduced zinc phosphate contents as a consequence of the synergistic interaction between zinc hypophosphite and the other components of the pigment mixture. The electrochemical noise technique proved to be adequate to monitor corrosion in painted panels and is able to detect corrosion under the paint film from very early stages. This paper identified the need to study synergism between anticorrosive pigments to try to reduce the phosphate content in anticorrosive paints.
\end{abstract}

Keywords. Pigments; paints; corrosion protection; synergism.

\section{Introduction}

Synergism is defined as a property by which two or more agents act together more effectively than either alone or a phenomenon where by the mixed effect of two and is greater than the sum of the two influences acting separately [1]. A number of studies have been reported on the synergistic inhibition of metallic corrosion [2]. Pigments mixtures, such as iron oxide with zinc ferrite, zinc chromate and/or zinc phosphate, have been studied electrochemically or in paints [35]. The reaction between zinc and lead compounds with the vehicles of certain paints such as azelaic acid has been studied for a long time [6]. The synergism between molybdate anion and zinc ions with and without nitrite ions as well as the interaction between molybdate ions with phosphate anion and zinc and/or calcium cation have been studied $[3,7,8]$ with very good results. Nowadays, together with zinc phosphate, zinc molybdophosphate is one of the non-lead, non-chrome anticorrosive pigments in the market.

The objective of this research was to study the synergistic behaviour between a first-generation phosphate pigment, a 'complementary' pigment (zinc oxide) and zinc hypophosphite in a pigment mixture which is commercially available. The anticorrosive behaviour of the commercial blend was evaluated by electrochemical tests. Then, different coatings were formulated employing the anticorrosive pigment mixture. The behaviour of the resulting paints was

\footnotetext{
*Author for correspondence (antifouling@ cidepint.gov.ar)
}

evaluated through accelerated test (salt spray chamber) and electrochemical noise technique. The electrochemical noise technique was proposed as a suitable tool to evaluate the behaviour of paints because no perturbation was applied to the system under study [9-13]. Noise resistance values $\left(R_{\mathrm{N}}\right)$, calculated from the measurements allowed to rank different coatings as good, fair and poor [14]; however, the values are not clearly related with the polarization resistance (calculated from DC measurements) except under certain conditions [15-17]. Records of freely changing potential and coupling current between two similar specimens were taken, at regular intervals, during the test period. From the mean values of each time series (potential and/or current), information could be gathered about the anticorrosive behavioiur of the paint. The quotient between the potential standard deviation and the current standard deviation of each time series is called the noise resistance. Data could also be analysed in the frequency domain $[10,12,18]$. In this paper, only results of the statistical analysis are reported.

\section{Experimental}

The inhibitive properties of a commercial pigment containing zinc phosphate, zinc hypophosphite and zinc oxide were evaluated by means of electrochemical test in pigments suspensions. This pigment mixture was also used as the inhibitive pigment in paints whose anticorrosive properties were assessed by accelerated and electrochemical tests. 
The composition of the commercial anticorrosive pigment mixture was determined by conventional analytical procedures. The presence of hypophosphite was confirmed by FTIR measurements. The solubility of the inhibitive mix was also determined by analytical techniques.

\subsection{Evaluation of inhibitive properties of the pigment suspension}

The corrosion potential of SAE 1010 steel electrode was monitored, as a function of time, in the corresponding pigment suspension (pigment mixture or zinc phosphate) in $0.025 \mathrm{M}$ sodium perchlorate, employing a saturated calomel electrode (SCE) as reference.

The morphology of the protective layer formed on the steel panel exposed to the anticorrosive pigment suspension was observed by scanning electron microscopy (SEM) employing a PHILLIPS SEM 505 coupled with an EDAX OX PRIME 10 (energy dispersed form) to determine the surface elemental composition. Polarization curves of a SAE 1010 steel electrode, with low surface roughness (mean peak-to-valley height $1.40 \mu \mathrm{m}$ ), were obtained after $6 \mathrm{~h}$ of exposure to the pigment mixture suspension in $0.5 \mathrm{M}$ sodium perchlorate solution. Sodium perchlorate solution was chosen as supporting electrolyte to avoid the intense corrosion produced by sodium chloride which could make it impossible to observe the different processes which take place on the electrode. A SCE was used as reference and a platinum grid as the counter-electrode. The swept began in the vicinity of the corrosion potential at a scan rate of $1 \mathrm{mV} \mathrm{s}^{-1}$. Similar curves were obtained for each component of the blend to determine its influence on the anticorrosive behaviour of the pigment mixture. Steel corrosion rate $\left(J_{\text {corr }}\right)$ and Tafel anodic and cathodic slops $(b+$ and $b-$, respectively) were determined from the polarization curves. Measurements were carried out with a Potentiostat-Galvanostat EG\&G PAR Model 273A plus SOFTCORR 352 software.

\subsection{Experimental paints formulating}

Three kinds of paints were formulated and elaborated; two of them of the epoxy type (a water-borne paint and a solvent-borne one) and the other an alkyd solvent-borne paint. The composition of all paints could be seen in table 1 .

Two anticorrosive pigment contents were evaluated: 15 and $30 \%$ by volume with respect of the total pigment content and the PVC/CPVC ratio was 0.8 as suggested elsewhere $[19,20]$. For water-borne epoxy paints the PVC was $20 \%$ to produce a more impervious coating. The procedure of elaboration and application of paints was described in previous research work [21].

\subsection{Performance of anticorrosive paints through accelerated and electrochemical tests}

Rusting (ASTM D 610) degree was evaluated on a set of painted panels in the salt spray chamber (ASTM B 117). Painted panels were evaluated after 1000, 1700 and $1950 \mathrm{~h}$ of exposure; the mean value of the obtained results was reported in this paper.

The electrochemical behaviour of painted steel was studied employing the electrochemical noise technique. The experimental arrangement for electrochemical noise measurements was that of the Beaker method [12]. All real data records were collected by simultaneously measuring the noise potential and the coupling current via zero resistance ammeter. The electrochemical cell had three electrodes: two symmetrical painted SAE 1010 steel ones and the SCE. The edges of the specimens were blanked off leaving $37 \mathrm{~cm}^{2}$ of the painted surface exposed to the electrolyte $(0.5 \mathrm{M}$ sodium perchlorate solution). The cell was put into a Faraday cage for electromagnetic shield. Potential and current noise spectra were obtained six times a day, during $1000 \mathrm{~s}$ at a sampling frequency of $1 \mathrm{~Hz}$. The sensitivity of the measuring device in the E-scale was $100 \mu \mathrm{V}$ and $50 \mathrm{nA}$ in current measurements. The mean value of each spectrum was then plotted against time. The noise resistance $\left(R_{\mathrm{N}}\right)$ was calculated as the quotient between the standard deviation of the potential-time series and the standard deviation of the coupling current record. The metallic surface, under the paint film, was examined by SEM after the electrochemical noise measurements were done. Examination was done on delaminated areas.

Table 1. Composition of paints as volume.

\begin{tabular}{|c|c|c|c|c|c|c|c|c|c|c|c|c|}
\hline \multirow[b]{3}{*}{ Paints } & \multicolumn{12}{|c|}{ Components } \\
\hline & \multicolumn{5}{|c|}{ Pigments } & \multicolumn{3}{|c|}{ Resins } & \multicolumn{3}{|c|}{ Solvents } & \\
\hline & Anticorrosive & $\begin{array}{l}\text { Titanium } \\
\text { dioxide }\end{array}$ & Talc & Barite & Mica & $\begin{array}{l}\text { Water- } \\
\text { borne } \\
\text { epoxy }\end{array}$ & $\begin{array}{l}\text { Solvent- } \\
\text { borne } \\
\text { epoxy }\end{array}$ & $\begin{array}{c}\text { Solvent } \\
\text { alkyd }\end{array}$ & Water & $\begin{array}{l}\text { Xylene } \\
\text { methylisobuthylketone } \\
\text { buthyl cellosolve } \\
(13 / 45 / 42 \% \text { by wt) }\end{array}$ & $\begin{array}{l}\text { White } \\
\text { spirit }\end{array}$ & Additives \\
\hline 1 & 1.8 & 2.6 & 2.5 & 2.8 & 2.3 & 47.7 & - & - & 38.9 & - & - & 1.4 \\
\hline 2 & 3.6 & 2.1 & 2.1 & 2.2 & 2.0 & 47.7 & - & - & 38.9 & - & - & 1.4 \\
\hline 3 & 3.0 & 2.6 & 7.2 & 7.2 & - & - & 55.8 & - & - & 24.2 & - & - \\
\hline 4 & 6.0 & 2.4 & 5.8 & 5.8 & - & - & 55.8 & - & - & 24.2 & - & - \\
\hline 5 & 3.0 & 2.6 & 7.2 & 7.2 & - & - & - & 55.8 & - & - & 24.2 & - \\
\hline 6 & 6.0 & 2.4 & 5.8 & 5.8 & - & - & - & 55.8 & - & - & 24.2 & - \\
\hline
\end{tabular}




\section{Results and discussion}

The composition of the commercial pigment mixture tested in this research was as follows: $41.6 \%$ of zinc phosphate $\left(\mathrm{Zn}_{3}\right.$ $\left.(\mathrm{PO} 4)_{2} \cdot 4 \mathrm{H}_{2} \mathrm{O}\right), 10.8 \%$ of zinc hypophosphite $\left(\mathrm{Zn}\left(\mathrm{PO}_{2} \mathrm{H}_{2}\right)_{2}\right.$. $\left.\mathrm{H}_{2} \mathrm{O}\right)$ and $47.6 \%$ of zinc oxide $(\mathrm{ZnO})$. The presence of hypophosphite anion was confirmed by the absorption band at $1700 \mathrm{~cm}^{-1}$ in the FTIR spectrum, which corresponds to the stretching of the $\mathrm{P}-\mathrm{H}$ bond. The solubility of the pigment mixture was determined according to ASTM D 2448 and found to be equal to $15 \mathrm{ppm}$ of $\mathrm{Zn}^{2+}$ and $13 \mathrm{ppm}$ of $\mathrm{PO}_{4}^{3-}$, being these values higher than those reported for zinc phosphate $[19,20]$.

\subsection{Evaluation of inhibitive properties of the pigment suspension}

The pigment mixture containing zinc hypophosphite slightly displaced the corrosion potential towards more positive values with respect to zinc phosphate alone at the beginning of the test period (figure 1).

The protective layer formed on steel in contact with the pigments mixture suspension was an uniform one and was mainly constituted by iron compounds (Fe: $85.6 \%)$ and a rather high zinc content, $14.4 \%$ (figure $2 \mathrm{a}$ ). The cavities on the surface are anodic in depth and cathodic near the

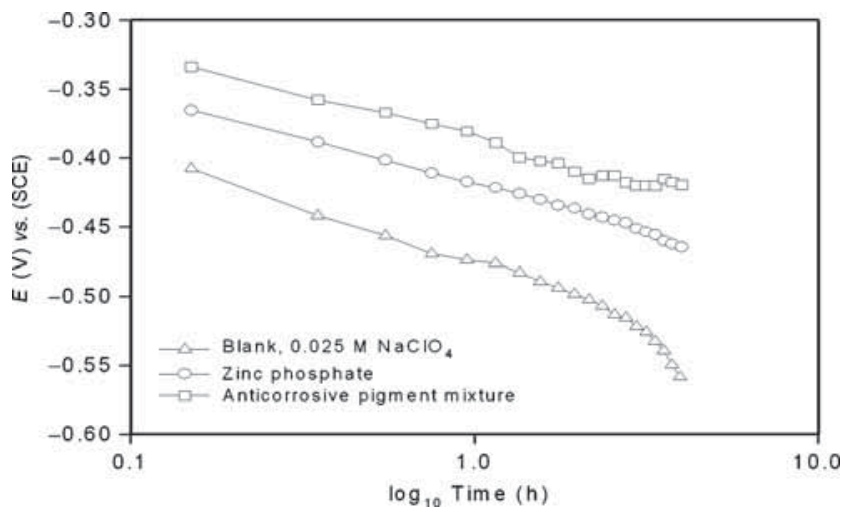

Figure 1. Corrosion potential of SAE 1010 steel in pigments suspensions. Electrolyte: $0.025 \mathrm{M} \mathrm{NaClO}_{4}$.
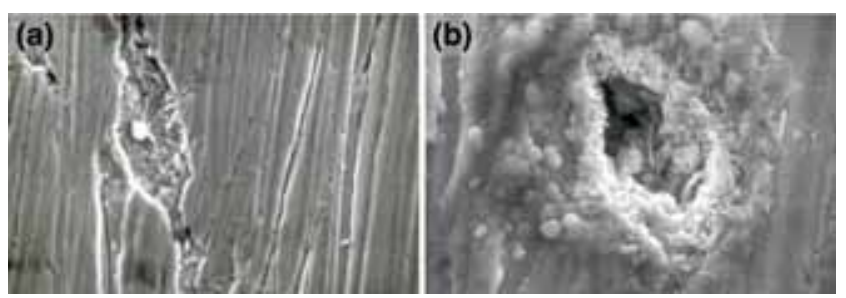

Figure 2. SEM micrograph of the SAE 1010 steel surface after $24 \mathrm{~h}$ in contact with the anticorrosive pigment suspension in 0.025 $\mathrm{M} \mathrm{NaClO}_{4}$. (a) Panoramic view $(1500 \times)$ and (b) oxide formations surrounding a cavity $(2500 \times)$. surface and, as a consequence, the composition of the protective layer surrounding the cavity was enriched in zinc compounds which precipitated as a result of the alkalinization of the cathodic areas. Globular formations observed in figure $2 \mathrm{~b}$ contained high amounts of $\mathrm{Zn}(58.3 \%)$ being Fe the rest.

Figure 3 depicts polarization curves for different suspensions containing zinc hypophosphite; one of these systems was similar to the commercially available anticorrosive blend. Results are compared with a blank containing the supporting electrolyte. The anodic branch of the polarization curve of the supporting electrolyte increased continuously as the electrode potential increased and the cathodic current was found to be $188 \mu \mathrm{A} \mathrm{cm}^{-2}$. The presence of zinc hypophosphite caused the electrode to passivate during the anodic scan, exhibiting a peak at $+605 \mathrm{mV}$ (peak current $179 \mathrm{~mA} \mathrm{~cm}{ }^{-2}$ ). The cathodic current was high and similar to that measured with the blank. The addition of zinc oxide and zinc phosphate to the solution also caused the electrode to passivate. Two overlapped peaks at $+127 \mathrm{mV}$ (peak current $2.99 \mathrm{~mA} \mathrm{~cm}^{-2}$ ) and at $+154 \mathrm{mV}$ (peak current $2.41 \mathrm{~mA} \mathrm{~cm}^{-2}$ ), respectively, appeared in the voltammogram. The presence of zinc oxide and zinc phosphate modified the passivity achieved with zinc hypophosphite, in the sense that it appeared at lower potentials and with much lower peak currents. The presence of these substances also diminished the cathodic current to $2.53 \mu \mathrm{A} \mathrm{cm}{ }^{-2}$. It was thought that zinc hypophosphite accelerated steel dissolution but the presence of zinc oxide and zinc phosphate, together with the products of steel dissolution, yielded the growth of an effective passive layer. This synergism is beneficial for steel passivation because not only anodic passivation was improved but also cathodic current diminished markedly. Results obtained with the commercial blend were similar; an anodic passivation peak was observed at $228 \mathrm{mV}$ (peak

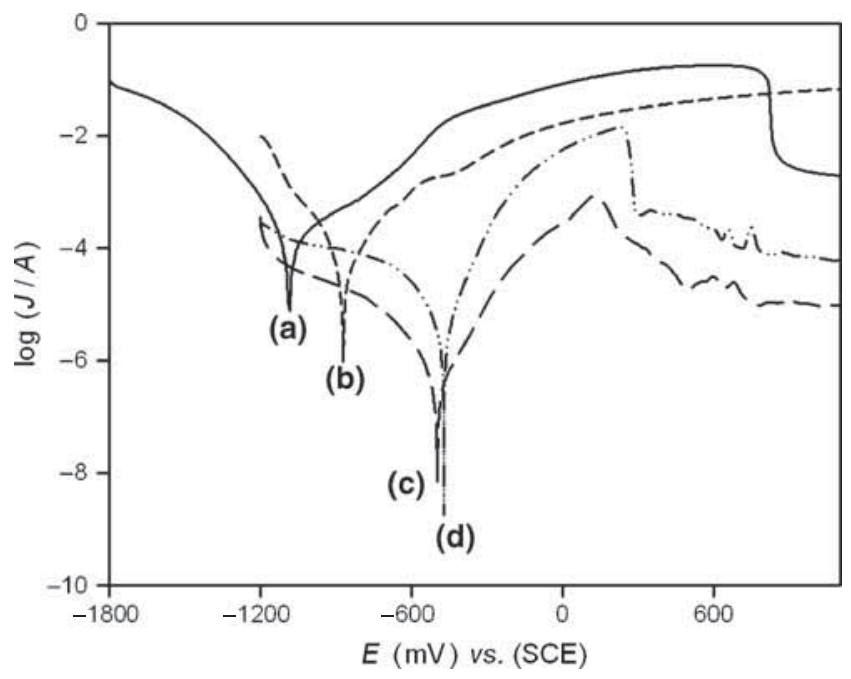

Figure 3. Polarization curves of the SAE 1010 steel electrode in the pigments suspensions after $6 \mathrm{~h}$ of exposure. Electrolyte: $0.5 \mathrm{M}$ $\mathrm{NaClO}_{4}$. Scan rate $3 \mathrm{mV} \mathrm{s}^{-1}$. (a) $0.1 \mathrm{M}$ zinc hypophosphite; (b) support electrolyte; (c) $0.1 \mathrm{M}$ zinc hypophosphite + zinc oxide + zinc phosphate and (d) anticorrosive pigment mixture. 
current $47.7 \mathrm{~mA} \mathrm{~cm}^{-2}$ ) and the oxygen current was also low $\left(11 \mu \mathrm{A} \mathrm{cm}^{-2}\right)$. In table 2 , the results obtained from Tafel linearization of the polarization curves can be seen. The corrosion current diminished when the anticorrosive pigment mixture was added to the supporting electrolyte, one order of magnitude. On the other hand, when zinc hypophosphite was incorporated, the corrosion current was increased almost 10 times. Tafel anodic slops varied from 44 to $360 \mathrm{mV}$, while cathodic slops varied from -40 to $-200 \mathrm{mV}$, indicating that different overpotential should be applied to increase the current 10 times.

\subsection{Performance of anticorrosive paints in accelerated tests}

Results obtained in the salt spray test, after 1950 h, showed that the best anticorrosive behaviour was achieved by waterborne epoxy (paints 1 and 2) and alkyd (paints 5 and 6) coatings. The performance of solvent-borne epoxy coatings was less satisfactory (figure 4). The water-borne epoxy paint exhibited a striking behaviour, obtaining a qualification 7 after $3700 \mathrm{~h}$ of testing. It was reported that similar paints formulated only with $30 \%$ of zinc phosphate behaved satisfactorily during $2400 \mathrm{~h}$ of exposure in the salt spray chamber [21]. Solvent-borne epoxy paints begun to fail, as an average, after $1950 \mathrm{~h}$ of exposure, while similar paints with $30 \%$ of zinc phosphate achieved an acceptable degree (qualification 7) up to $1700 \mathrm{~h}$ of exposure [21,22]. The results obtained with the alkyd coating containing the pigment mixture tested in this research, were clearly superior to those obtained with zinc phosphate alone. The former paint underwent $1950 \mathrm{~h}$ of testing with a qualification equal to 9, while paints formulated with $30 \%$ of zinc phosphate begun to fail at $1700 \mathrm{~h}$, as reported in the literature [22]. This improved behaviour could be attributed to the reaction of zinc oxide with oleorresinous binders, such as alkyds, to generate zinc soaps which are thought to inhibit corrosion [23].

The employment of the tested anticorrosive pigment mixture led to very good results even with the lowest pigment content (15\%); indeed, no significant differences

Table 2. Tafel parameters from polarization curves.

\begin{tabular}{lccccc}
\hline Pigments & $\log \left(J_{\text {corr }}\right)$ & $J_{\text {corr }}\left(\mathrm{A} \mathrm{cm}^{-2}\right)$ & $b^{+}(\mathrm{mV})$ & $b^{-}(\mathrm{mV})$ & $E_{\text {corr }}(\mathrm{mV})$ \\
\hline Support electrolyte & -5.0 & $1.0 \times 10^{-5}$ & 44 & -40 & -871 \\
Zinc oxide & -5.2 & $6.3 \times 10^{-6}$ & 18.8 & -20.3 & -287 \\
Zinc hypophosphite & -3.9 & $1.3 \times 10^{-4}$ & 360 & -150 & -1085 \\
Zinc hypophosphite + zinc oxide + zinc phosphate & -6.2 & $6.3 \times 10^{-7}$ & 160 & -200 & -498 \\
Anticorrosive pigment mixture & -5.7 & $2.0 \times 10^{-6}$ & 80 & -100 & -472 \\
\hline
\end{tabular}

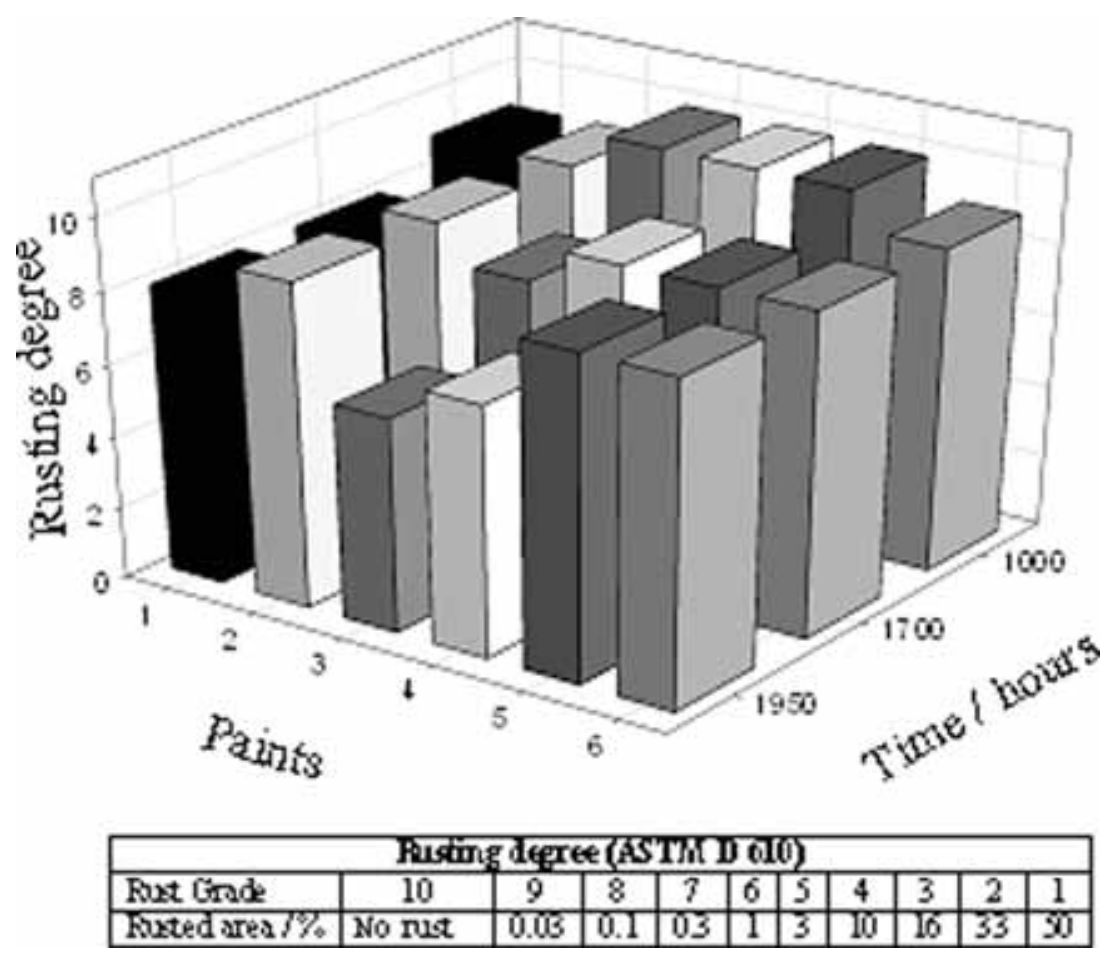

Figure 4. Rusting (ASTM D 610) degree of painted panels exposed to the salt spray chamber (ASTM B 117). 
were observed between both pigment loads employed in this research.

It was supposed that the pigment mixture restrained the formation of corrosion products which can disrupt through the paint film. In fact, after paint removal of panels exposed to the salt spray chamber, it was noticed that thick black iron oxide films developed under blisters and a non-expansive oxide layer grew in the remainder of the surface. This dark oxide was, presumably, ferrous oxide; so, it speculated that the main function of zinc hypophosphite was to prevent the oxidation of ferrous species. Moreover, zinc hypophosphite activates steel dissolution but iron ions, in combination with zinc oxide and zinc phosphate, generated a very efficient protective layer.

The foregoing results pointed out that it is possible to reduce the zinc phosphate content in the paint film if a suitable additive, such as zinc hypophosphite, is incorporated to the formulation to enhance its protective ability. The two anticorrosive pigment loadings employed in this research (15 and $30 \% \mathrm{v} / \mathrm{v}$, respectively) contained 7.3 and $14.6 \%$ of zinc phosphate. This calculation was made on the basis of the pigment composition given in the first paragraph of this section and the zinc phosphate density $\left(3.0 \mathrm{~g} \mathrm{~cm}^{-3}\right)$. These very low zinc phosphate contents could not provide a satisfactory anticorrosive behaviour as reported in previous work $[19,20,22,24]$. In previous research, it was demonstrated that zinc oxide could improve the inhibitive action of zinc phosphate [25]. In brief, the good anticorrosive performance of tested paints could be attributed to the synergism of the three compounds included in the anticorrosive mixture.

\subsection{Performance of anticorrosive paints in electrochemical tests}

The mean values of the noise potential of paint 1 begun to decrease after 60 days of immersion and descended below $-400 \mathrm{mV}$ after 70 days of immersion (figure 5). After 140 days of immersion, the noise potential remained fluctuating around $-440 \mathrm{mV}$, the value matched by the steel electrode in the pigment suspension (figure 1). The coupling current began to increase just when the noise potential showed a net decreasing tendency. Bands observed in potential and current records during the first days of immersion were attributed to the formation of a protective layer. At the end of the test period, coupling current were increased and $R_{\mathrm{N}}$ decreased, which led to the conclusion that the protective layer was increasing its thickness continuously. This behaviour was thought to be stimulated by the presence of zinc hypophosphite whose influence on steel dissolution was discussed previously. Moreover, as a consequence of the long exposure time, the paint film delaminated; so the active area as well as the coupling current were increased. However, no red iron oxide was detected, by visual examination, under the paint film.

Steel coated with paint 2 exhibited mean potential values which initially decreased to approximately $-520 \mathrm{mV}$ and, then, increased continuously up to $-375 \mathrm{mV}$ to finally fluctuated around $-420 \mathrm{mV}$ due to the presence of the inhibitive pigment mixture (figure 6). Current reached high
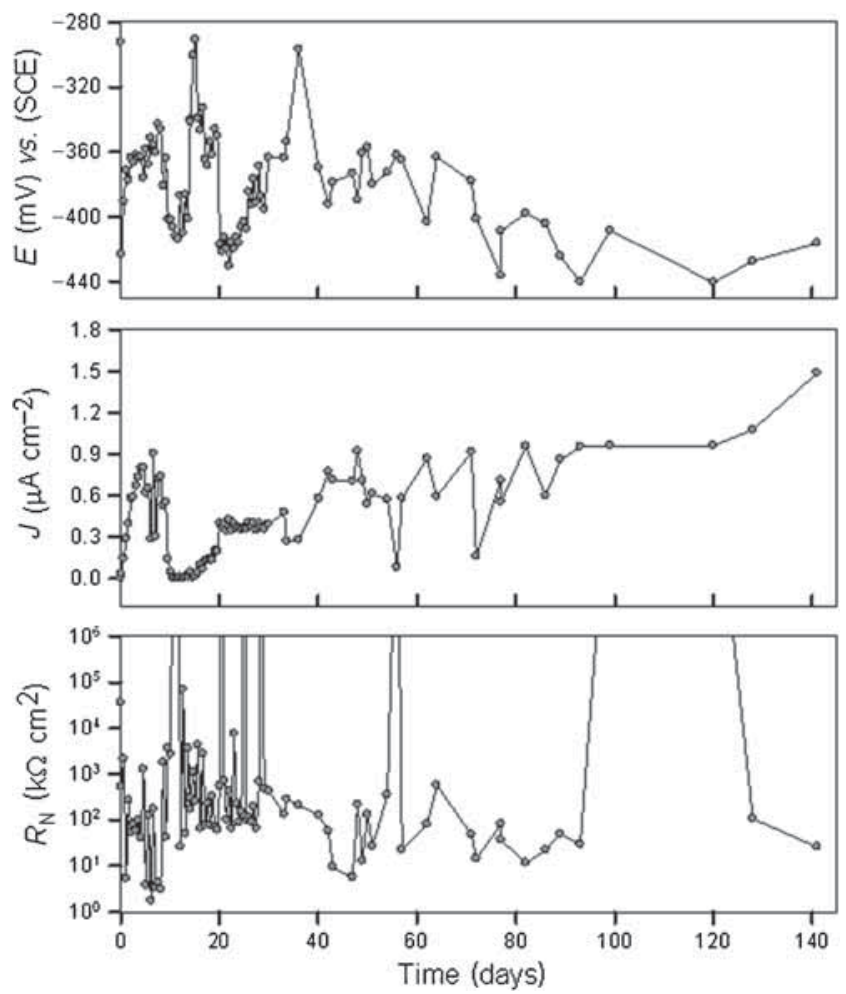

Figure 5. Mean values of noise potential, coupling current and noise resistance as a function of time, for paint 1 , in $3 \% \mathrm{NaCl}$.
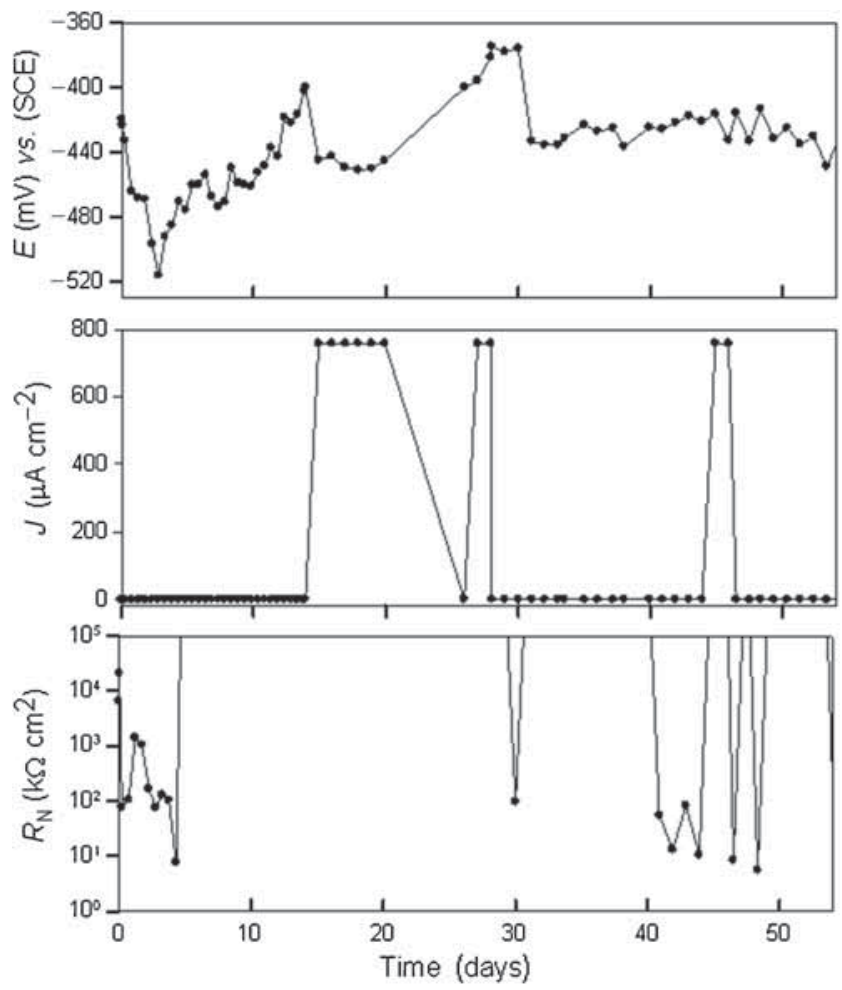

Figure 6. Mean values of noise potential, coupling current and noise resistance as a function of time, for paint 2 , in $3 \% \mathrm{NaCl}$. 
values during certain periods of time but, as a general rule, remained close to zero; thus, indicating the protection of the steel substrate. Mean noise resistance was higher than $10^{3} \mathrm{k} \Omega \mathrm{cm}^{-2}$.

Potential mean values of steel coated with paint 3 presented an increasing tendency up to 55 days of immersion to finally fluctuated around -440 to $-400 \mathrm{mV}$ (figure 7), the corrosion potential attained by the steel electrode in the anticorrosive pigment suspension (figure 1). The coupling current oscillated during the whole test period because of the passivation of the steel substrate (figure 7). $R_{\mathrm{N}}$ was very high at the beginning of the test period and, then, fluctuated between $10^{3}$ and $10^{4} \mathrm{k} \Omega \mathrm{cm}^{-2}$, showing an increasing tendency at the end of the test.

Paint 4 was similar to paint 3 in nature, but with $30 \%$ of anticorrosive pigment content. The mean noise potential increased only up to 30 days of immersion and, then, descended to lower values (figure 8) to finally increase after 100 days of exposure. Oscillations during the first month of the testing could be attributed to a repassivation process. The coupling current showed an important increasing tendency and surpassed $1 \mu \mathrm{A} \mathrm{cm} \mathrm{cm}^{-2}$ beyond 60 days of exposure to final decay as time elapsed, just when mean noise potential increased. The noise resistance was rather high and it exhibited a maximum, just when the noise potential was attaining the most positive values and the coupling current showed the lowest ones. Steel seemed to react intensely with the
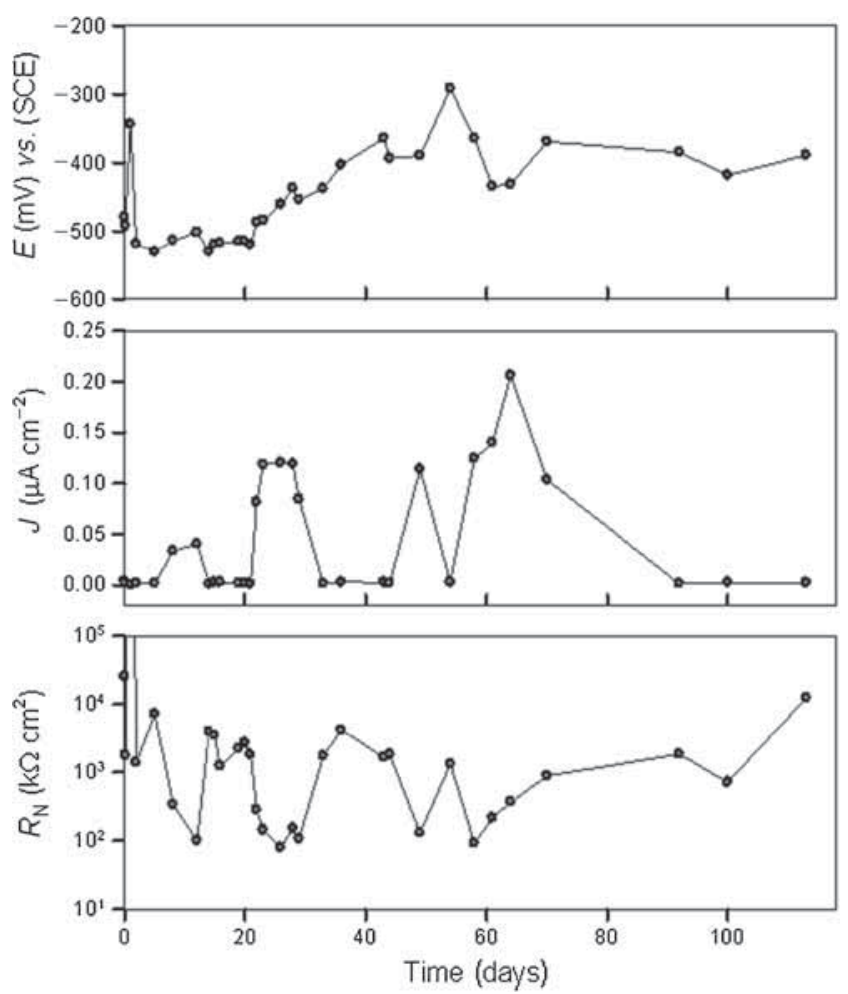

Figure 7. Mean values of noise potential, coupling current and noise resistance as a function of time, for paint 3, in $3 \% \mathrm{NaCl}$.
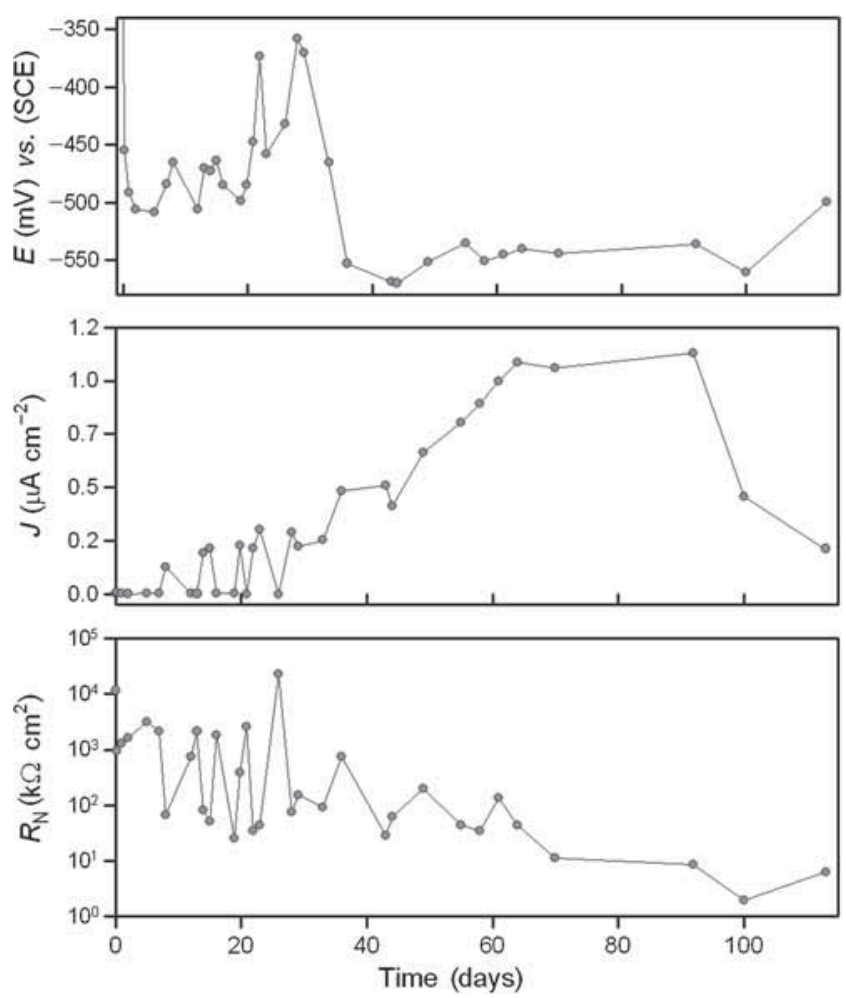

Figure 8. Mean values of noise potential, coupling current and noise resistance as a function of time, for paint 4 , in $3 \% \mathrm{NaCl}$.
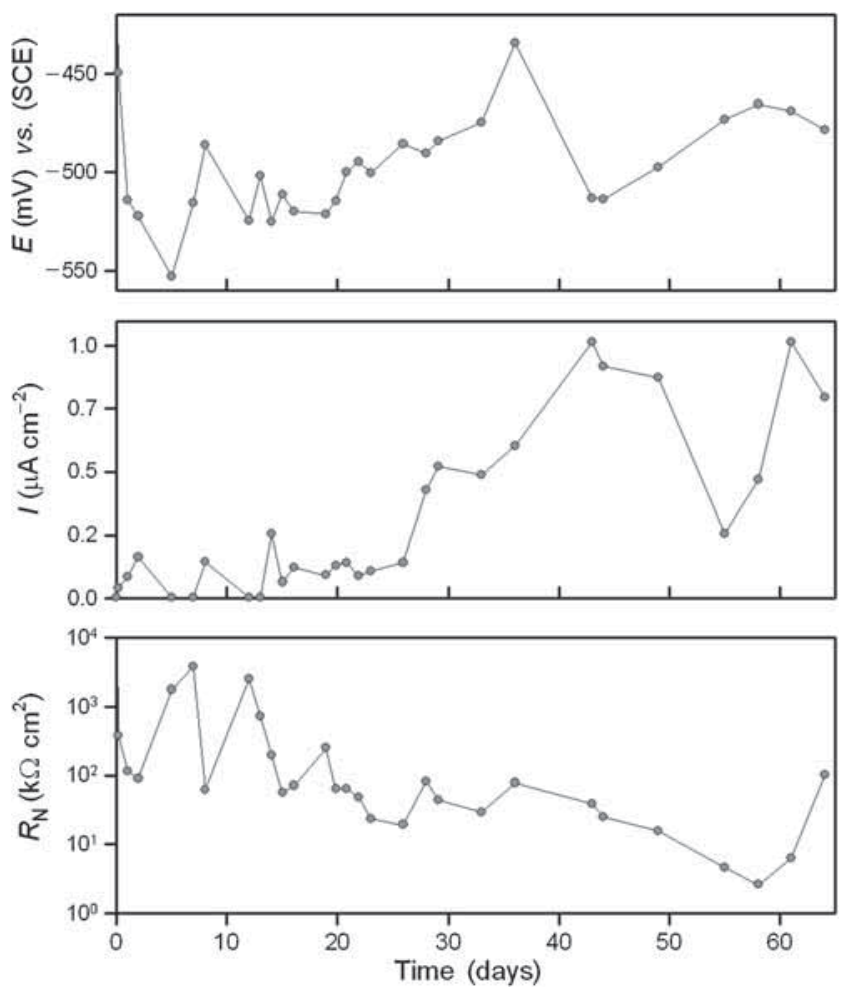

Figure 9. Mean values of noise potential, coupling current and noise resistance as a function of time, for paint 5 , in $3 \% \mathrm{NaCl}$. 
anticorrosive pigment mixture and generate a protective layer between 40 and 100 days of immersion.

The behaviour of alkyd paints (paints 5 and 6) was also influenced by the pigment content, but in a different way. The paint with the lower pigment content (paint 5) generated a record where the mean noise potential varied around
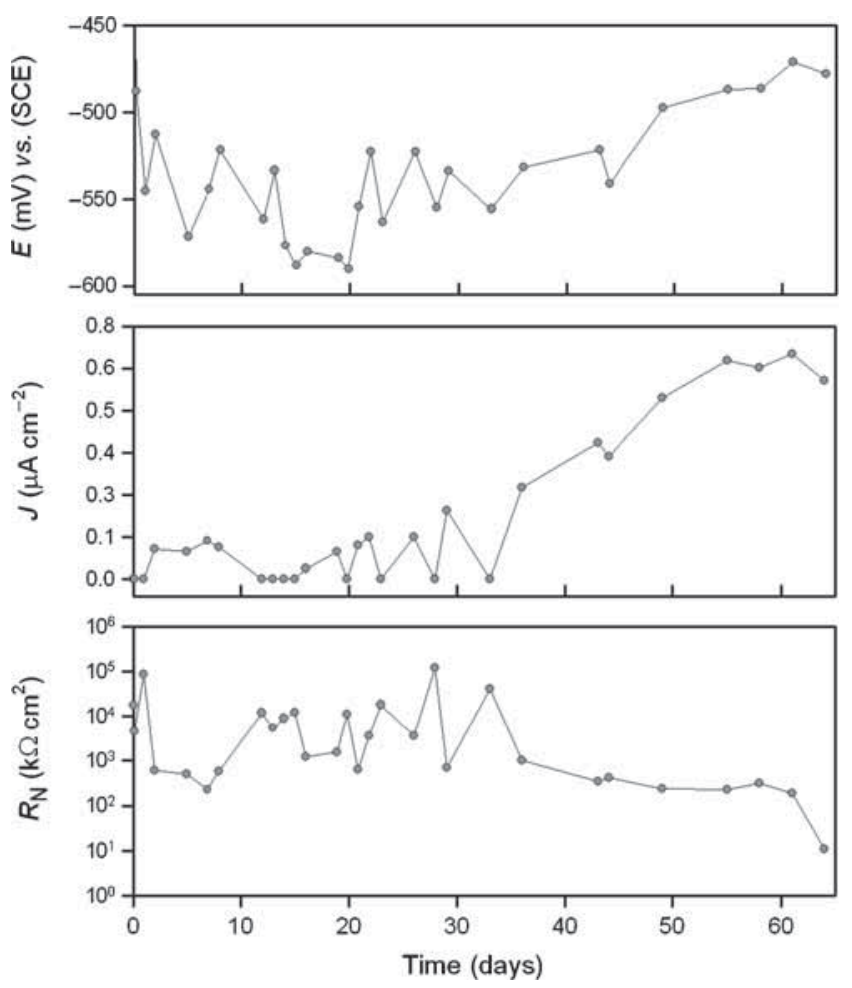

Figure 10. Mean values of noise potential, coupling current and noise resistance as a function of time, for paint 6 , in $3 \% \mathrm{NaCl}$. $\sim 500 \mathrm{mV}$ from the very beginning of the test (figure 9). The coupling current maintained rather low values during 2025 days and, then, begun to increase and reached values as high as $1 \mu \mathrm{A} \mathrm{cm}^{-2}$. The noise resistance, $R_{\mathrm{N}}$ oscillated during the first fortnight of immersion as if there were certain restraints to the corrosion reaction but, afterwards, it maintained lower values. $R_{\mathrm{N}}$ increased beyond 60 days of immersion and mean coupling current decreased as a consequence of steel passivation.

The noise potential record of paint 6 (figure 10) presented a decreasing tendency till 20 days of immersion and then it increased until it matched typical values of the corrosion potential of steel in the anticorrosive pigment suspension. The coupling current maintained low values during 33 days of immersion and, at the same time, during that period, the noise resistance, $R_{\mathrm{N}}$ oscillated and reached the highest values of the test period. Beyond this date, it was supposed that substrate dissolution took place at higher rate because the coupling current increased and reached values higher than $0.6 \mu \mathrm{A} \mathrm{cm}^{-2}$ and the noise resistance was too low.

Electrochemical noise measurements, in accordance with the salt spray test (ASTM B 117), showed that anticorrosive paints protected steel adequately. As a general rule, mean noise potential remained fluctuating close to the value obtained with steel in the pigment suspension. Coupling current rarely exceeded $1 \mu \mathrm{A} \mathrm{cm}^{-2}$ and average $R_{\mathrm{N}}$ values were rather high $\left(10^{2}-10^{3} \mathrm{k} \Omega \mathrm{cm}^{-2}\right)$ during the most part of the test period. Good results were obtained in the the salt spray up to $1750 \mathrm{~h}$ of testing.

From results obtained in the present research, it may be seen that the electrochemical noise technique is sensitive enough to detect the changes taking place under the paint film before they could be appreciated by visual examination as it was proposed in ASTM B 610. In this sense, the electrochemical noise technique clearly showed the
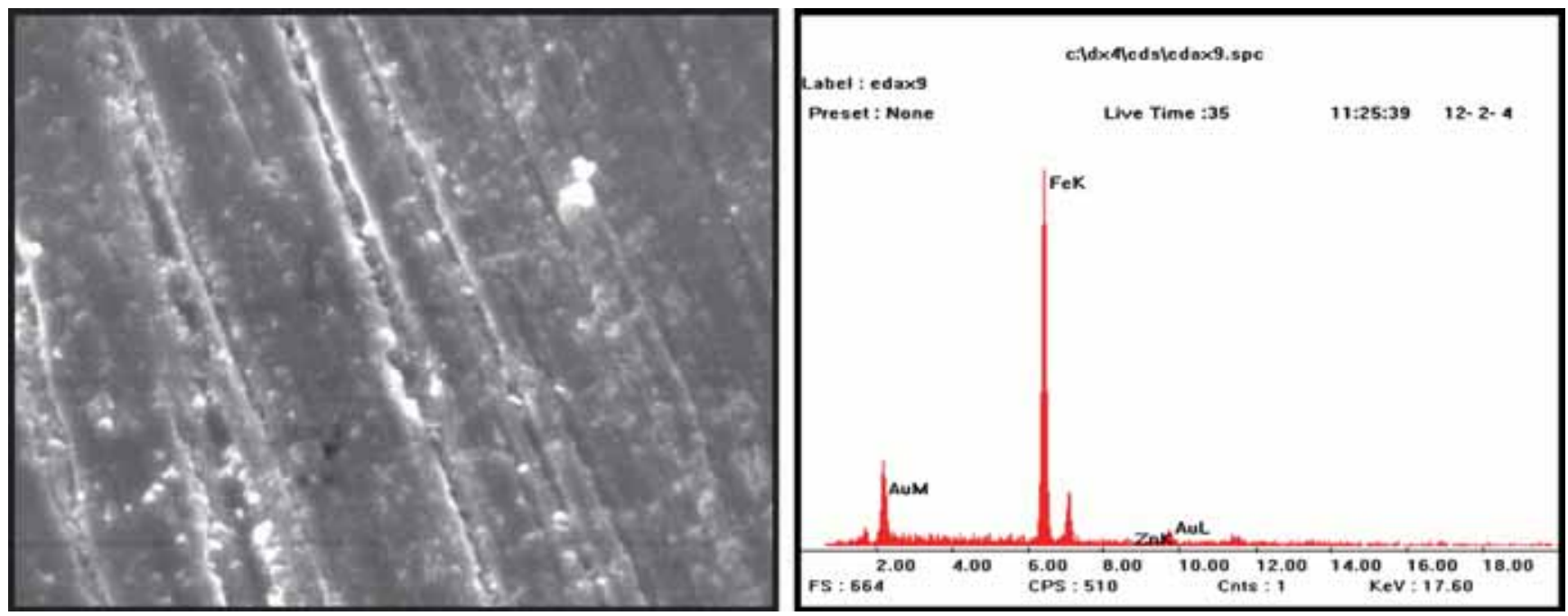

Figure 11. SEM micrograph $(2500 \times)$ and EDAX spectrum of the steel surface after delamination of coating 2 in the electrochemical assay. Electrolyte: $3 \% \mathrm{NaCl}$. 

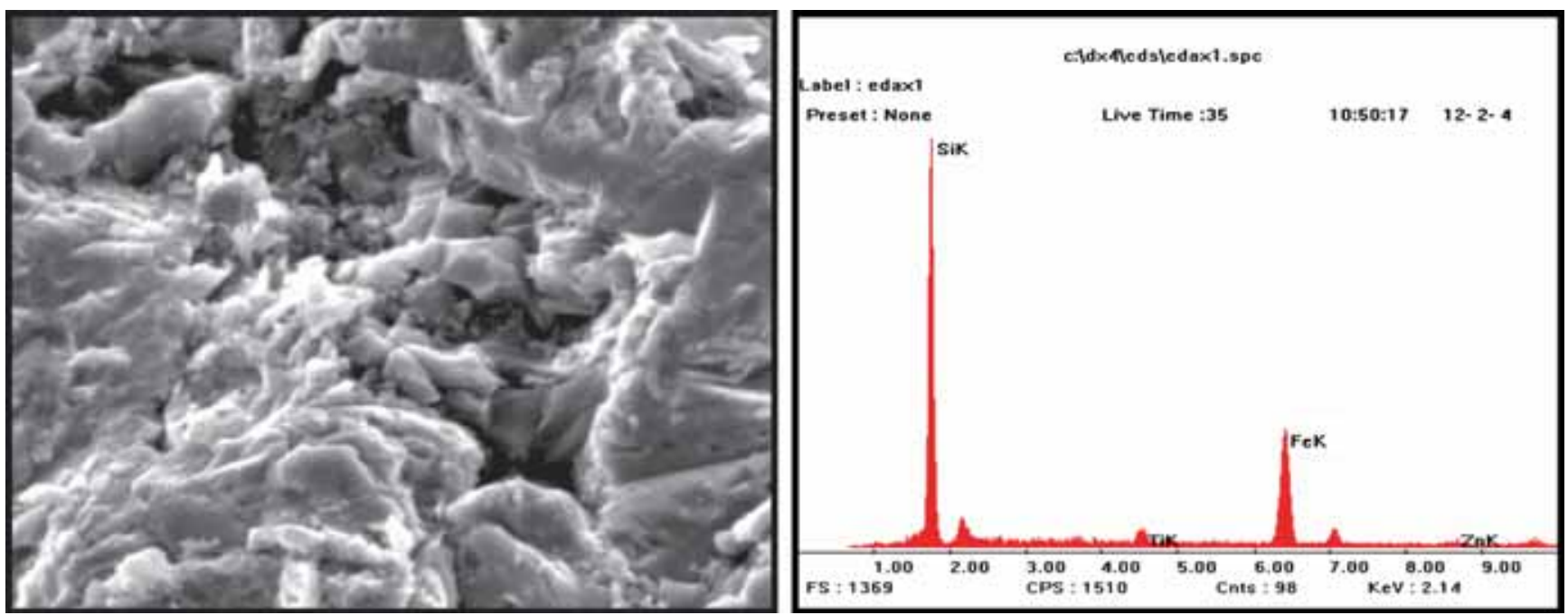

Figure 12. SEM micrograph $(2500 \times)$ and EDAX spectrum of the steel surface after delamination of coating 6 in the electrochemical assay. Electrolyte: $3 \% \mathrm{NaCl}$.
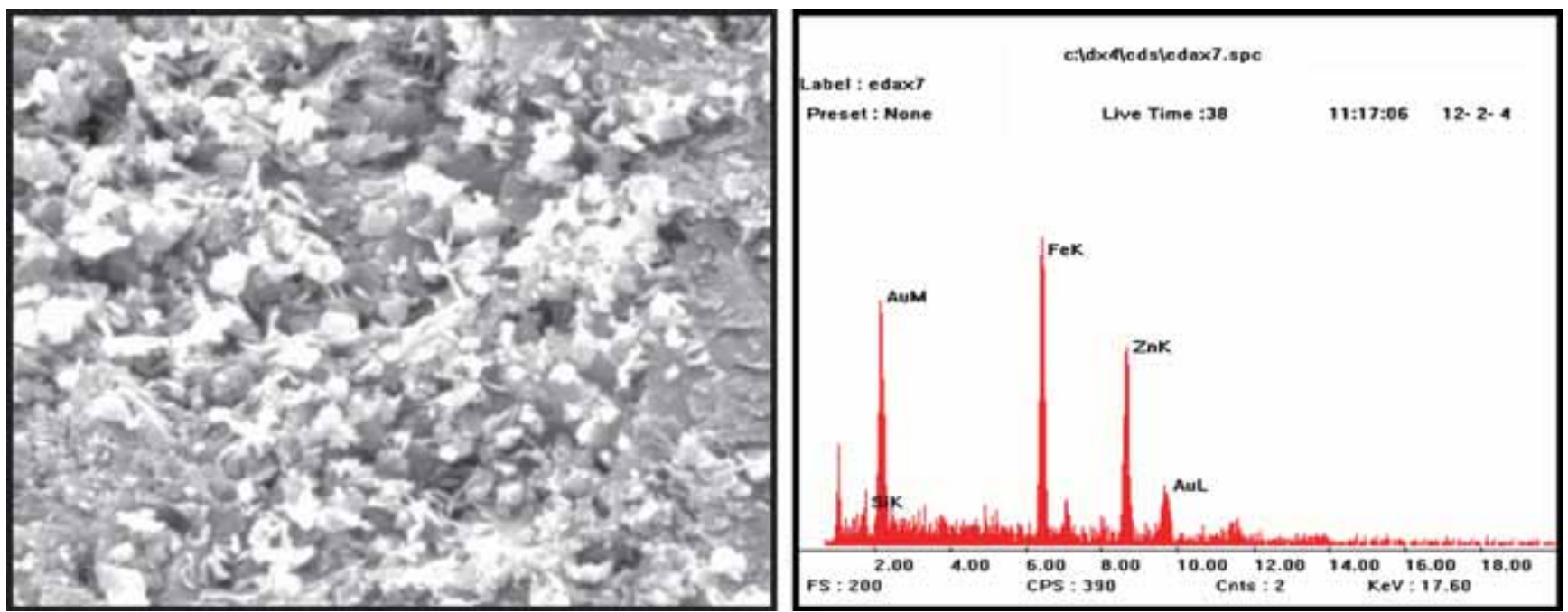

Figure 13. SEM micrograph $(2500 \times)$ and EDAX spectrum of the steel surface after delamination of coating 4 in the electrochemical assay. Electrolyte: $3 \% \mathrm{NaCl}$.

different behaviour of the paints through its characteristic parameters.

In most cases, as a consequence of both the long exposure time to the saline environment and the flowing current between short-circuited specimens, paints delaminated. The delaminated areas appeared, by visual examination, free of red oxides and were examined by SEM to analyse the nature of the protective layer, while the composition was determined by EDAX. The protective layer was constituted mainly by iron oxides, growing in a more or less smooth layer (figure 11) or as gel-like particles with certain tendency to form crystals (figure 12). Sometimes, small white particles were observed on the oxide layer (figure 13), these small formations contained high amounts of zinc as it could be appreciated from the EDAX spectrum. No expansive iron oxides were detected in every case.

\section{Conclusions}

Accelerated tests showed that the pigment mixture is suitable to formulate water-borne epoxy coatings and alkyd paints which showed an improved anticorrosive behaviour. The very good anticorrosive behaviour obtained with the pigment mixture could be explained in terms of the synergism of its three active components. The mean function of zinc hypophosphite seemed to be to accelerate steel dissolution to form a better protective layer. Zinc compounds could also help to polarize cathodic sites. Good results were obtained with the lowest pigment content. This fact implies that the phosphate content could be reduced significantly on employing zinc hypophosphite and zinc oxide in combination with zinc phosphate.

The electrochemical noise technique is sensitive enough to detect the changes taking place under the paint film before 
they could be appreciated by visual examination as it was proposed in ASTM B 610.

While it has been demonstrated that synergistic behaviour of pigments through accelerated laboratory tests, still it does not know if this behaviour is achieved in outdoor tests that are nowadays being carried out.

\section{Acknowledgements}

We are grateful to CONICET (Consejo Nacional de Investigaciones Científicas y Técnicas), CICPBA (Comisión de Investigaciones Científicas de la Provincia de Buenos Aires) and UNLP (Universidad Nacional de La Plata) for their sponsorship to do this research.

\section{References}

[1] Hodges S, Uphues W and Tran M 1997 Surf. Coat. Inter. 80 178

[2] Aramaki K, Hagiwara M and Nishihara H 1987 Corros. Sci. 27487

[3] Meyer G 1965 Moderne weisse Inhibitor pigmente und deren Kombinationen in Anstrichsystemen. Farbe + Lack 71113

[4] Rozados E, Vetere V and Carbonari R 1978 Corrosión y Protección 93

[5] Robu C, Orban N and Varga G 1987 Polym. Paint Colour J. 177566

[6] Johnson W 1994 J. Coat. Technol. 6647

[7] Jabeera B, Shibli S and Anirudhan T 2001 Corros. Prevent. Cont. 665
[8] Kumari A, Sreevalsan K and Shibli S 2001 Corros. Prevent. Cont. 983

[9] Gabrielli C and Keddam M 1992 Corrosion 48794

[10] Xiao H and Mansfeld F 1994 J. Electrochem. Soc. 141 2332

[11] Bierwagen G, Jeffcoate C, Junping L, Balbyshev S, Tallman D and Mills D 1996 Progr. Organ. Coat. 2921

[12] Kearns J, Scully J, Roberge P, Reichert D and Dawson J 1996 Electrochemical noise measurement for corrosion applications, in: ASTM STP 1277. West Conshohocken, USA

[13] Mansfeld F, Xiao H, Han L and Lee C 1997 Progr. Organ. Coat. 3089

[14] Mansfeld F, Han L T, Lee C C, Chen C, Zhang G and Xiao H 1997 Corros. Sci. 39255

[15] Mills D J and Mabbutt S 2000 Progr. Organ. Coat. 3941

[16] Deyá M C, del Amo B, Spinelli E and Romagnoli R 2013 Progr. Organ. Coat. 76525

[17] Chen J and Bogaerts W 1995 Corros. Sci. 371839

[18] Bloomfield P 2000 Fourier analysis of time series: an introduction in applied probability and statistics (USA: John Wiley \& Sons)

[19] Gerhard A and Bittner A 1986 J. Coat. Technol. 5859

[20] Bittner A 1989 J. Coat. Technol. 61111

[21] Blustein G, Deyá M, Romagnoli R and del Amo B 2005 Appl. Surf. Sci. 2521386

[22] Blustein G, del Amo B and Romagnoli R 2000 Pigment Resin Technol. 29100

[23] Kroustein M 1991 J. Oil Colour Chem. Assoc. 74124

[24] del Amo B, Romagnoli R, Vetere V and Hernández L 1998 Progr. Organ. Coat. 3328

[25] Deya M, Romagnoli R and del Amo B 2004 Corros. Rev. 221 